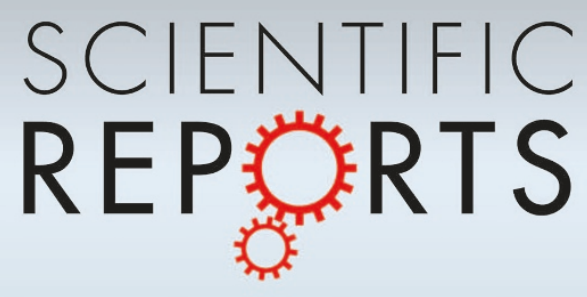

OPEN

SUBJECT AREAS:

APPLIED PHYSICS

COMPUTATIONAL SCIENCE

APPLIED MATHEMATICS

Received

28 March 2014

Accepted

14 May 2014

Published

20 June 2014

Correspondence and requests for materials should be addressed to Y.-A.de M. (yva@mit.

edu)

\section{The Strength of the Strongest Ties in Collaborative Problem Solving}

\author{
Yves-Alexandre de Montjoye' ${ }^{1}$, Arkadiusz Stopczynski ${ }^{1,2}$, Erez Shmueli', Alex Pentland' \& \\ Sune Lehmann ${ }^{2,3}$
}

${ }^{1}$ Media Lab, Massachusetts Institute of Technology, ${ }^{2}$ Department of Applied Mathematics and Computer Science, Technical
University of Denmark, ${ }^{3}$ Niels Bohr Institute, University of Copenhagen.

Complex problem solving in science, engineering, and business has become a highly collaborative endeavor. Teams of scientists or engineers collaborate on projects using their social networks to gather new ideas and feedback. Here we bridge the literature on team performance and information networks by studying teams' problem solving abilities as a function of both their within-team networks and their members' extended networks. We show that, while an assigned team's performance is strongly correlated with its networks of expressive and instrumental ties, only the strongest ties in both networks have an effect on performance. Both networks of strong ties explain more of the variance than other factors, such as measured or self-evaluated technical competencies, or the personalities of the team members. In fact, the inclusion of the network of strong ties renders these factors non-significant in the statistical analysis. Our results have consequences for the organization of teams of scientists, engineers, and other knowledge workers tackling today's most complex problems.

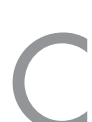

omplex problems in science, engineering, or business are being solved by teams of people working closely with one another, each with the help of their network. In science, modern experiments require the collaboration and specialization of many individuals ${ }^{1}$. For example, a modern Nature paper can have more than $100 \mathrm{co}_{\text {-authors }}{ }^{2}$ and the number of co-authors of PNAS papers has more than doubled over the last 20 years, reaching an average of 8.4 co-authors per paper ${ }^{3}$. In businesses, teams of knowledge workers have become the basic unit carrying out work ${ }^{4}$. Our ability to solve complex problems increasingly depends on teams of scientists, engineers, or knowledge workers and their extended information networks $s^{5,6}$.

Qualitative and quantitative study of high-performing teams-an interdependent collection of individuals working towards a common goal where members share individual and mutual responsibility for the outcome ${ }^{7}$-has been an ongoing effort in the social, management, and science of science ${ }^{8-13}$. Previous studies focused on how the personalities, technical or cognitive abilities, or the existence of previous collaborations of team members explain team performance. Recent quantitative studies investigated the determinants of high-performing teams by studying their structure or pattern of communication $\mathrm{s}^{14-19}$.

Accessing to the right piece of information is central to solving complex problems. This information, however, often only exists in the form of advice, expertise, implicit knowledge, or experience and flows through social ties. Consequently, the structure of social interactions has been shown to enhance or hinder access to such resources. Building on advances in social network analysis, empirical research showed the impact of an individual's information or collaboration network on her performance ${ }^{20-26}$. Amongst others, the impact of an individual position in the information network has been investigated through measures of node degree, centrality, structural holes, closure, and social diversity ${ }^{27-32}$.

Both within-team and extended information networks are useful. Within-team networks allow for engagement, collaboration, and the higher level of information sharing needed for teams to perform ${ }^{15}$. Frequent interactions between team members have been shown to help them become familiar with one another and to positively impact their teamwork ${ }^{33}$. Extended networks of informal ties of team members have been shown to be the vector for key exchanges of information ${ }^{15}$. Information often flows through these ties despite the existence of formal coordination and communication mechanisms. These informal extended ties have been shown to be particularly important in competitive environments ${ }^{34}$. This work, at the intersection of information networks and team performance, studies the problem solving abilities of teams as a function of the within-team network structure and extended information network in a real working environment. We show that, for both within team and extended ties networks, only the strongest ties matter. 


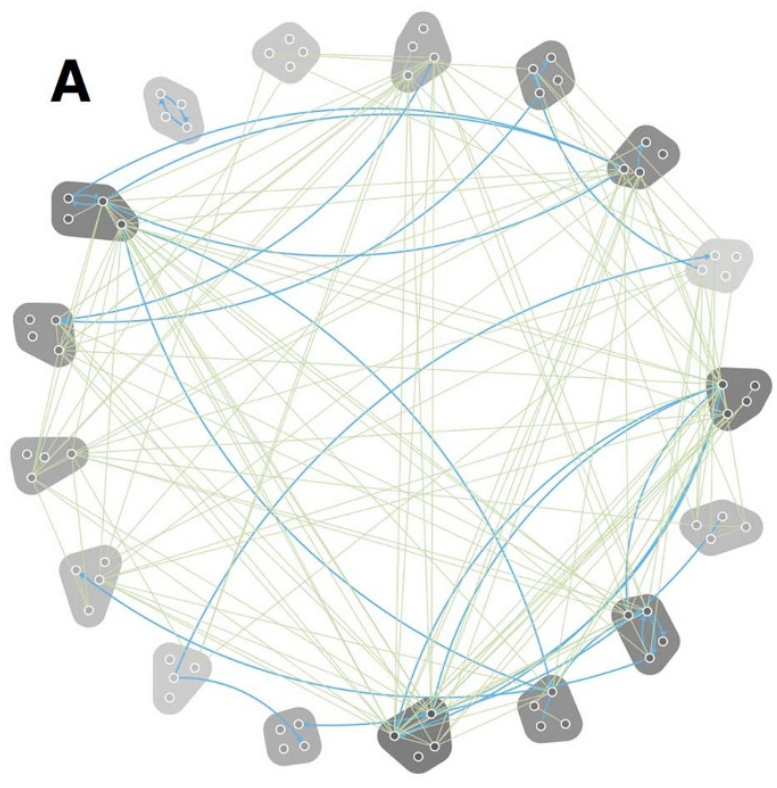

B
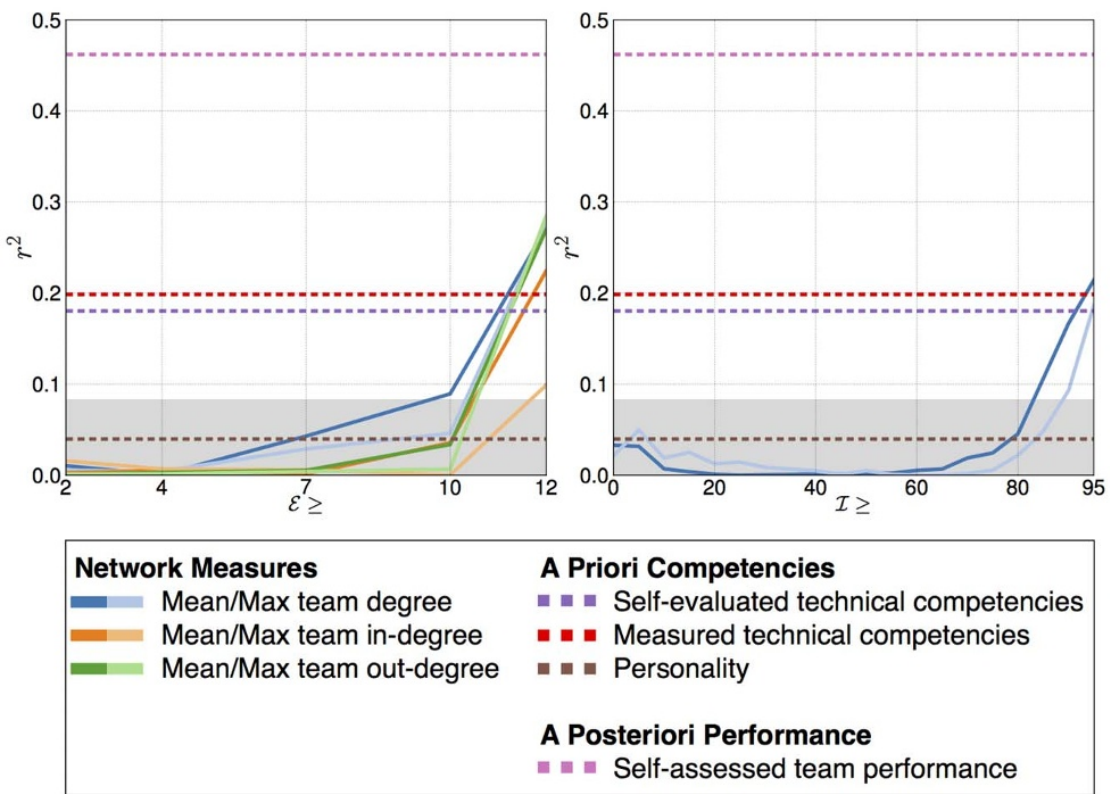

Figure $1 \mid$ (A) Network of strongest expressive ties ( $\mathcal{E} \geq 12$ - blue), instrumental ties ( $\mathcal{I} \geq 95$ - green), and the team participants were assigned to for the first project. Color saturation is the performance of the teams, where darker is higher. (B) Correlation between expressive tie strength and team performance. (C) Correlation between instrumental tie strength and team performance. For both expressive and instrumental ties, the position in the network of strong ties is more important than other a priori characteristics of the team, such as self-evaluated and measured proficiency or personality. The gray areas indicate values with $p>0.05$.

\section{Results}

We examine the performance of 45 assigned teams of four students during one semester. Eighty participants worked in teams on three separate projects for one course. Teams changed for every project so that no one worked with the same person twice. Following the behavioral tradition of organizational learning, we measure performance by focusing on predefined objective outcomes ${ }^{35}$ : the grades given by the lecturer to the team reports. Participants specifically mark their individual contribution, which motivates them to actively participate.

There has been considerable ambiguity about what constitutes a tie when studying social and information networks, as well as the structure of organizations $s^{36,37}$. In his definition of Phillos relationships, Karckhardt ${ }^{23}$ focuses on interaction, affection, and time as the basic characteristics of ties. This prompted Lincoln to propose to define ties as either instrumental or expressive ${ }^{17,38}$. We adopt this definition here.

Expressive ties reflect friendships and include an affective factor. They have been theorized to create incentives to treat others positively and fairly. We measured expressive ties using a questionnaire at the beginning of the experiment. Participants were asked to report their friendship levels $(\mathcal{E})$ on a $0,2,4,7,10,12$ scale, following the standard local grading system, with zero being "I do not know this person," four "an acquaintance," and twelve "one of my best friends" 

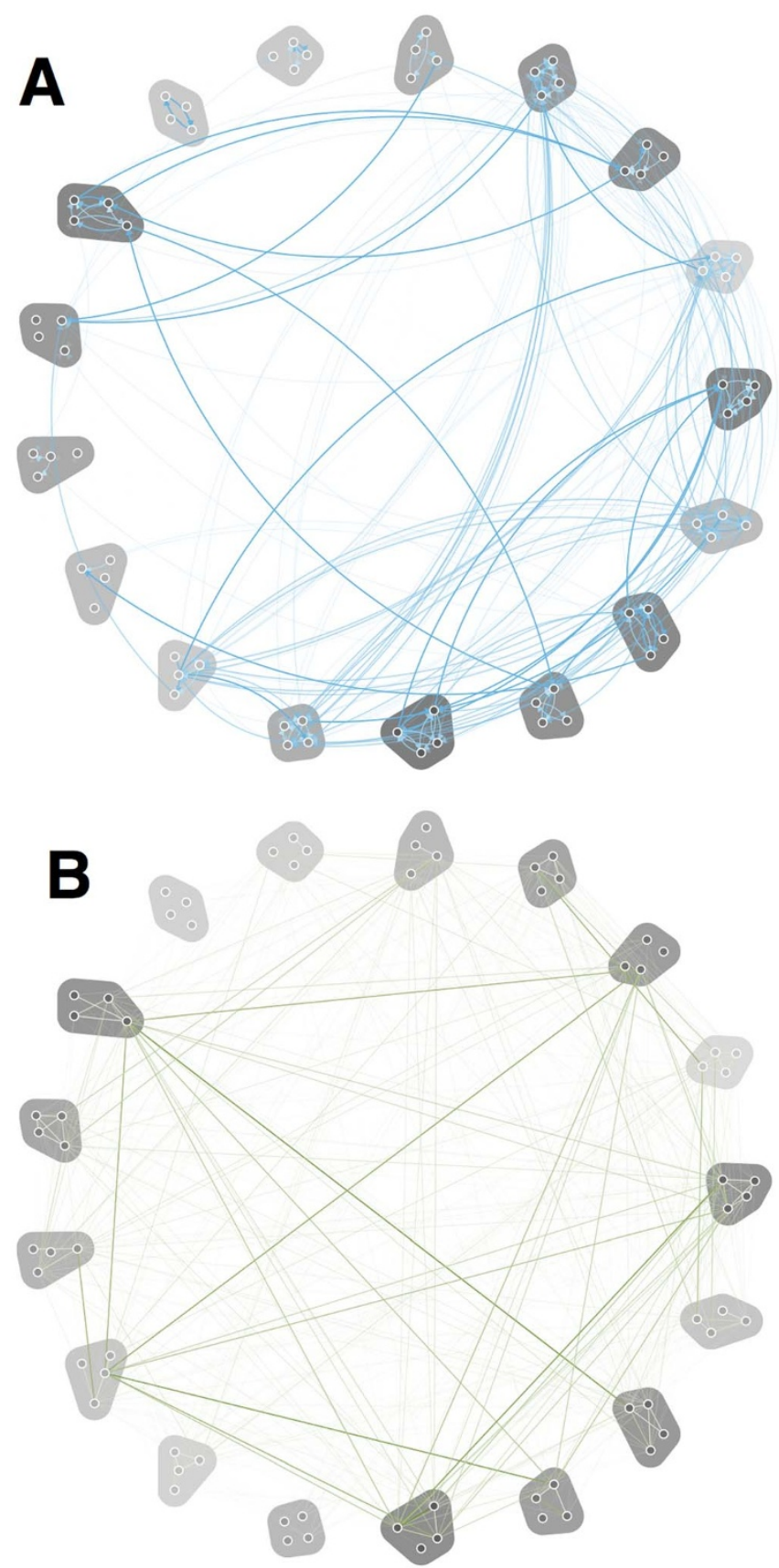

Figure $2 \mid$ Networks of instrumental and expressive ties, as well as assigned teams for the first project. Color saturation, where darker is higher, is the performance of the team and strength of the edges.

(A) Directed network of expressive ties of strength four and above.

(B) Undirected network of the $20 \%$ strongest instrumental ties.

Figure 1 shows the network of the strongest expressive and instrumental ties.

[see Methods]. We take friendship as a school-related measure of closeness. Fig. 2A shows the directed network of expressive ties, as well as the teams we assigned participants to for the first project.

Instrumental ties usually arise in professional settings, between colleagues or collaborators interacting and spending time together. They have been shown in the performance literature to create opportunities for the exchange of information ${ }^{23}$, to develop an esprit de corps $^{15}$, and to allow for colleagues or collaborators to gain interpersonal familiarity ${ }^{33}$. We consider time spent in physical proximity as a proxy for instrumental ties ${ }^{39,40}$. The logs of the university wifi system indicates the building in which participants' devices were. Using this information, we construct a weighted undirected network of time spent together over the course of the semester $(\mathcal{I})$ on a 0 to 100 scale [see Methods]. Fig. 2B shows the undirected network of instrumental ties.

Finally, the impact of tie strength on information propagation and knowledge transfer has been discussed in the social network, sociology, and science of science literature. It has however been considered in the form of either strong or weak ties, with research showing benefits for both ${ }^{21}$. In his seminal article on job searches, Granovetter showed that opportunities such as information about jobs usually flow through weak ties ${ }^{22}$. Subsequent work showed these distant and infrequent weak ties to be useful in the diffusion of information, advice, and ideas ${ }^{41-43}$. However, because they are more accessible or willing to help, strong ties have been shown to be essential to the transfer of complex information and tacit knowledge $e^{23-25,31}$. In organizational settings, strong ties have been shown to reduce conflicts $^{44}$ and to be crucial in dealing with stressful or unusual situations ${ }^{23}$. While quantifying what constitutes a strong and weak tie might be difficult, the effect of the expected benefits as a function of tie strength can be quantified.

We show that, given a simple linear model, the impact of tie strength on performance is highly nonlinear; only the strongest ties matter. We compute various network measures considered in the social network, collaboration network, and team performance literature such as the mean team degree, maximum team in-degree, etc ${ }^{17}$. All these measures display a nonlinear performance gain with tie strength; only the strongest expressive and instrumental ties (resp. $\mathcal{E} \geq 12$ and $\mathcal{I} \geq 95$ ) explain part of the team performance variance [Fig. 1]. All the network measures for the strongest ties are furthermore highly consistent internally $(\alpha=.940)^{45}$. The correlation between team performance and mean team degree is $r^{2}=.272(p$ $<.05)$ for strongest expressive ties and $r^{2}=.214(p<.05)$ for the strongest instrumental ties. In comparison, the correlation between team performance with the weakest expressive and instrumental ties is respectively $r^{2}=.010$ and $r^{2}=.034$ (both $p>.05$ ). This implies that (1) for both within-team and extended networks, only the strongest expressive and instrumental ties have an actual impact on the performance of the teams, and (2) the more expressive ties a team has, the better it performs.

Network measures of the strongest ties explain team performance better than other a priori measures, making them not significant most of the time. At the beginning of the experiment, participants took a 6-questions technical competencies test on the topic at hand, filled out a personality questionnaire, and were asked to self-evaluate how knowledgeable they were about the topic. The six technical questions were averaged as measured technical competency. The strongest ties in both the expressive and instrumental ties networks explain more of the variance than any of the team competencies considered: the mean or maximum of either the self-evaluated competencies, measured competencies, or personality [Fig. 1 and Methods]. The maximum self-evaluated and measured technical competencies, or personality, were systematically less explanatory than their mean values. None of the personality measures alone or combined as factors are significant. When taken as the only independent variable in a linear model, both mean self-evaluated $(p=.004)$ and mean measured technical proficiency $(p=.002)$ are significant. However, adding mean team degree of the strongest ties to both linear models makes both of them not significant $(p>$ .05 ). Mean team degree for expressive ties has $p$-values of .009 when combined with mean self-evaluated competencies and .014 when combined with mean measured competencies (respectively .043 and .094 for instrumental ties).

Network measures of both expressive and instrumental ties explain performance better than self-evaluated and measured technical competencies, or personality. As a measure of comparison, participants were also asked to fill out a short questionnaire when 


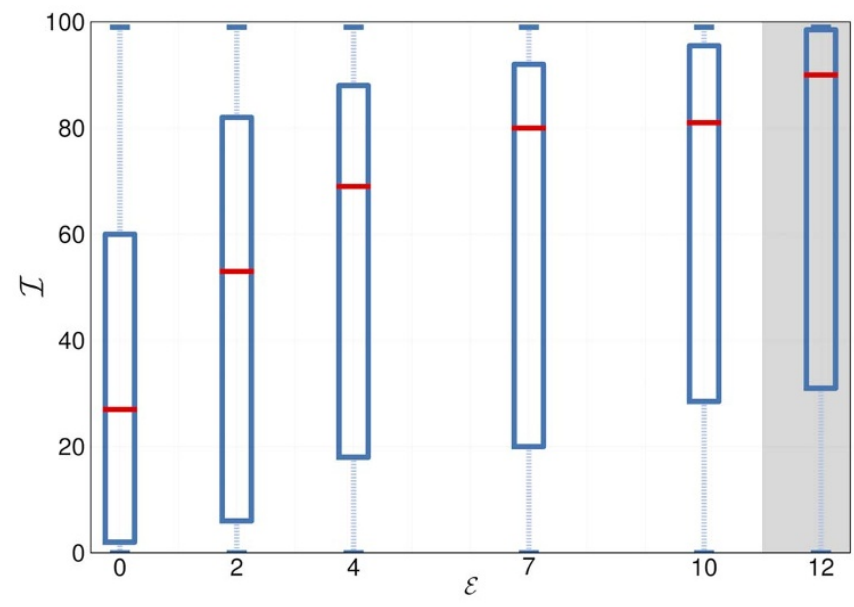

Figure $3 \mid$ As expected, the strength of ties in expressive and instrumental networks is not independent. The distribution of $\mathcal{I}$ for various $\mathcal{E}$ is however broad. Instrumental tie strength for the strongest expressive ties $(\mathcal{E}=12$ - in grey) has a large support. This means that the strongest ties in both networks really help explain performance.

handing in their projects. In this questionnaire, they were asked how they felt their team performed for this particular project. We expected this a posteriori measure to be the best indicator of team performance as self-assessment has been shown to be a reliable indicator of team performance ${ }^{46}$. It indeed was. However, while a posteriori self-assessed team performance explains nearly half of the variance $\left(r^{2}=.462, p<.001\right)$, it is only two times what is explained by our a priori strong ties measures.

\section{Discussion}

Temporal precedence has been often neglected in team performance, collaboration networks, and social network research ${ }^{19,47}$. Our experimental design allows us to answer the question of temporal precedence between expressive network structure and team performance. Does a dense network structure help a team to perform well or does a performing team create dense networks? In this study, we measured the network of expressive ties before the experiment started. We then assigned participants to teams, and we see a positive correlation between the strongest expressive ties and team performance.

Our results hold in both expressive and instrumental networks. Our expressive network is measured through traditional questionnaires, while our instrumental network is measured through sociometric means. We do not however expect the strength of a tie in the two networks to be independent as we are, for example, likely to spend more time with our friends. Fig. 3 shows that, while we indeed spend more time with our strongest expressive ties, the distribution of instrumental strength is still broad. This means that ties in both networks really help explain performance.

Tie strength, a variable often ignored, is in fact crucial for understanding teams' problem solving abilities. In our experiment, the project-based work completed by the participants can be characterized as non-routine and complex. Teams were presented with complex problems which focused on creative thinking and applying gained knowledge in a novel context.

To conclude, these results imply that weak ties between scientists, engineers, or other knowledge workers are unlikely to enhance access to information or to help performance. Very strong ties inside teams and between units or research teams are needed. The problem solving abilities of teams of scientists or knowledge workers tackling today's most complex problems could be greatly improved upon by creating very strong instrumental and expressive ties.

\section{Methods}

Setup. This experiment took place during a full semester course (13 weeks) at a large western university [See Fig. 4] ${ }^{48}$. The course was an advanced course, involving work with high-level programming, data modelling, and simple machine learning. At the beginning of the course, 80 out of the 95 students agreed to participate in the experiment and filled in an initial questionnaire. During the semester, participants successively worked on 3 projects in teams assigned by us. $N=45$ teams containing only participants are analyzed in this paper. Participants also answered right after handing-in their project report how they felt their team performed on a 1 to 5 scale: "How do you think your team did." Participants were informed that this self-assessed

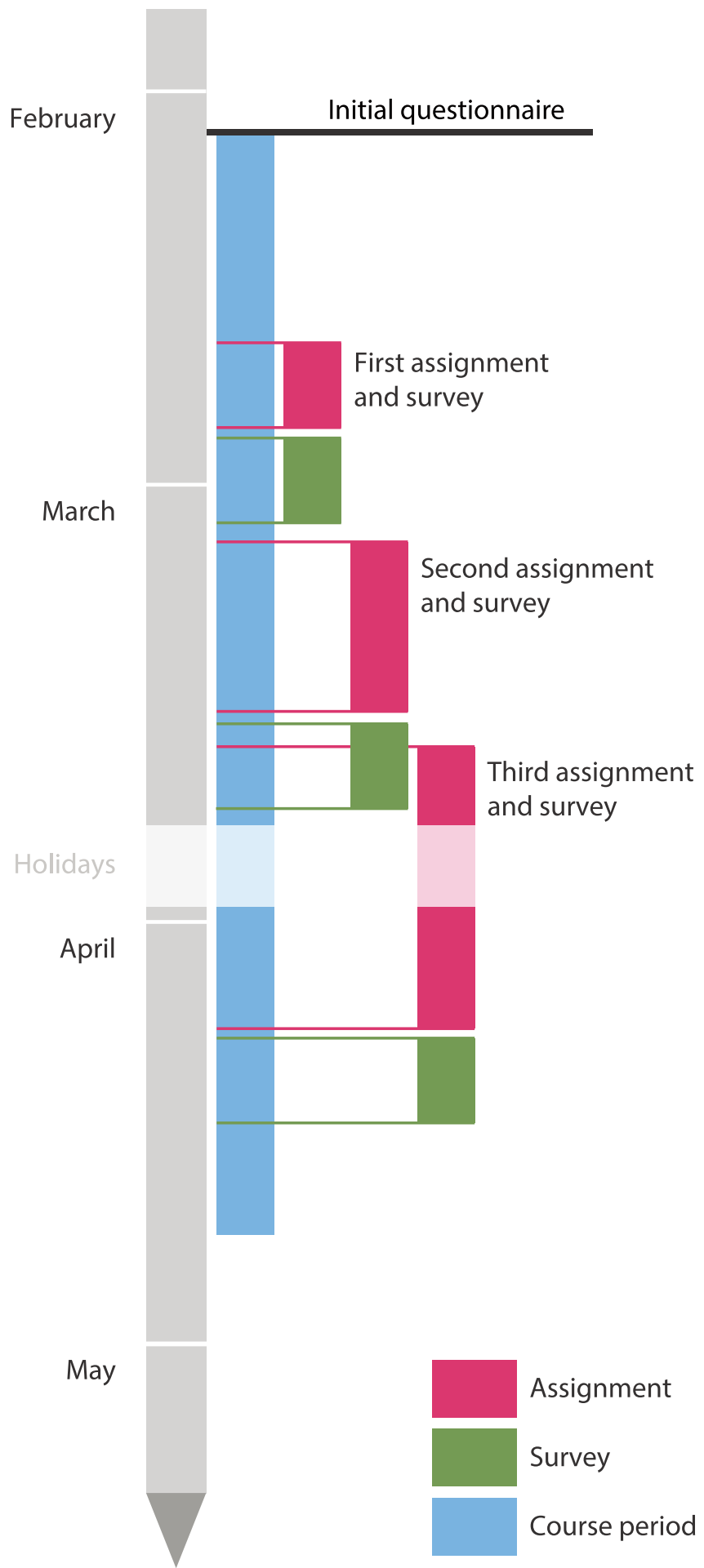

Figure 4 | Timeline of the study. Students agree to participate in the study and fill in the initial questionnaire. They are then assigned to team, complete their assignment, and are asked how well they think their team did. 
performance would not be seen by the lecturer, nor used in the grading process. The team projects were evaluated by the lecturer taking the difficulty of the assignment into account. The assignments focused on handling and visualizing social data, machine learning, and network analysis with students solving coding exercises, answering theoretical questions, and analyzing their results. At the university, students are encouraged to and commonly work and solve tasks in teams.

Initial questionnaire. At the beginning of the experiment, we asked participants about their self-reported proficiency on a 1-5 scale ("Would you consider yourself a beginner (1) or an expert (5) for this course?"). We also presented them with 6 technical questions assessing their skills related to the course and their personality $(\mathrm{BFI}-10)^{49}$.

Expressive ties. At the beginning of the experiment, we asked participants to rate how well they knew all the other participants. We used the standard grading scale (0-12), which all participants are familiar with: " 0 - I do not know this person," "2 - I recognize this person, but we never talked," " 4 - Acquaintance (we talk or hang out sometimes)," "7 - Friend," "10 - Close friend," "12 - One of my best friends". The list of participants to rate was presented as a webpage that included the participants' full names and university profile pictures.

The graphs of expressive ties were created by removing all links weaker than a given value. For example, $\mathcal{E} \geq 7$ would be the network with only ties of strength at least 7 . We calculated the in- and out-degrees of all nodes in the directed network, as well as their degree in the undirected network. The undirected network was created by considering only reciprocated ties after having removed the links weaker than a given value. Results are similar with all three measures [Fig. 1].

Instrumental ties. Participants have to login on their devices (smartphones, computers, etc) to use the university wifi system. This allows us to know which building a device was connected to with a resolution of 10 minutes. We infer instrumental ties from the observed co-occurrences using 10 minute time bins. The tie strength $S_{i, j}$ between participants $i$ and $j$ is given by ${ }^{50}$ :

$$
S_{i, j}=\sum_{t, b} \frac{c_{i, j, t, b}}{N_{t, b}}
$$

where $c_{i, j, t, b}$ is 1 if participants were present in the same building $b$ at the same time $t$ and 0 if otherwise. $N_{t, b}$ is number of participants in building $b$ at time $t$. We created the graphs of the wifi-based co-occurences by percentiles. For example, $\mathcal{E} \geq 70$ would be the network with the $30 \%$ strongest ties.

Teams. We assigned the participants into teams of four, as required by the course lecturer. We assigned students to new teams for each of the three projects so that no student was with the same person in team more than once. To find a balance among within and between team ties, we optimized the entropy of the motifs and the number of edges within teams while adding a penalty for missing motifs using a greedy algorithm [see SM].

Model. The effects of ties of all strength, self-evaluated, and measured technical competencies and self-assessed team performance on the performance of teams were evaluated by computing Pearson's product-moment coefficient between the team grade and the mean or the maximum of the measure of interest on a per team basis. The effect of personality was evaluated using both an average of the five personality traits of the team members as well as jointly modeled using a linear model with team grade as dependent variable. Finally, the effect of adding network measures to the selfevaluated and measured technical competencies and personalities of teams members were evaluated using a linear model.

1. de Solla Price, D. J. Little science, big science... and beyond (Columbia University Press New York, 1986).

2. Greene, M. The demise of the lone author. Nature 450, 1165-1165 (2007).

3. Börner, K., Maru, J. T. \& Goldstone, R. L. The simultaneous evolution of author and paper networks. PNAS 101, 5266-5273 (2004).

4. Beyerlein, M. M., Johnson, D. A. \& Beyerlein, S. T. Advances in interdisciplinary studies of work teams: Knowledge work in teams, Vol. 2. (Elsevier Science/JAI Press, 1995).

5. Wuchty, S., Jones, B. F. \& Uzzi, B. The increasing dominance of teams in production of knowledge. Science 316, 1036-1039 (2007).

6. Lander, E. S. et al. Initial sequencing and analysis of the human genome. Nature 409, 860-921 (2001).

7. Hackman, J. R. \& Oldham, G. R. Work redesign (Addison-Wesley, 1980).

8. Hong, L. \& Page, S. E. Groups of diverse problem solvers can outperform groups of highability problem solvers. PNAS 101, 16385-16389 (2004).

9. Stokols, D., Hall, K. L., Taylor, B. K. \& Moser, R. P. The science of team science: overview of the field and introduction to the supplement. American Journal of Preventive Medicine 35, S77-S89 (2008).

10. Hackman, J. R. The design of work teams. Ariel 129, 32-197 (1987).

11. Hackman, J. R. \& Hackman, J. R. Groups that work (and those that don't): Creating conditions for effective teamwork (Jossey-Bass San Francisco, 1990).

12. Cummings, J. N. \& Cross, R. Structural properties of work groups and their consequences for performance. Social Networks 25, 197-210 (2003).
13. Sanna, L. J. \& Parks, C. D. Group research trends in social and organizational psychology: Whatever happened to intragroup research. Psychological Science $\mathbf{8}$, 261-267 (1997).

14. Saavedra, S., Hagerty, K. \& Uzzi, B. Synchronicity, instant messaging, and performance among financial traders. PNAS 108, 5296-5301 (2011).

15. Pentland, A. The new science of building great teams. Harvard Business Review $\mathbf{9 0}$, 60-69 (2012).

16. Wu, L., Waber, B., Aral, S., Brynjolfsson, E. \& Pentland, A. Mining face-to-face interaction networks using sociometric badges: Predicting productivity in an it configuration task. Available at SSRN 1130251 (2008).

17. Balkundi, P. \& Harrison, D. A. Ties, leaders, and time in teams: Strong inference about network structures effects on team viability and performance. Academy of Management Journal 49, 49-68 (2006).

18. Yang, H.-L. \& Tang, J.-H. Team structure and team performance in is development: a social network perspective. Information \& Management 41 335-349 (2004)

19. Guimerà, R., Uzzi, B., Spiro, J. \& Amaral, L. A. N. Team assembly mechanisms determine collaboration network structure and team performance. Science 308, 697-702 (2005).

20. Newman, M. E. The structure of scientific collaboration networks. PNAS 98, 404-409 (2001).

21. Aral, S. \& Van Alstyne, M. The diversity-bandwidth trade-off. American Journal of Sociology 117, 90-171 (2011).

22. Granovetter, M. S. The strength of weak ties. American journal of sociology 1360-1380 (1973).

23. Krackhardt, D. The strength of strong ties: The importance of philos in organizations. Networks and organizations: Structure, form, and action 216, 239 (1992).

24. Ghoshal, S., Korine, H. \& Szulanski, G. Interunit communication in multinational corporations. Management Science 40, 96-110 (1994).

25. Hansen, M. T. The search-transfer problem: The role of weak ties in sharing knowledge across organization subunits. Administrative science quarterly $\mathbf{4 4}$, 82-111 (1999).

26. Peng, M. W. \& Luo, Y. Managerial ties and firm performance in a transition economy: The nature of a micro-macro link. Academy of management journal 43, 486-501 (2000).

27. Blansky, D. et al. Spread of academic success in a high school social network. PloS one 8, e55944 (2013).

28. Aral, S., Brynjolfsson, E. \& Van Alstyne, M. Information, technology and information worker productivity: Task level evidence (2007).

29. Soda, G., Usai, A. \& Zaheer, A. Network memory: The influence of past and current networks on performance. Academy of Management Journal 47, 893-906 (2004).

30. Vaquero, L. M. \& Cebrian, M. The rich club phenomenon in the classroom. Sci. Rep. 3 (2013)

31. Abbasi, A. \& Altmann, J. On the correlation between research performance and social network analysis measures applied to research collaboration networks. In 44th Hawaii International Conference on Systems Science (HICSS-44), Jan. 4-7, Hawaii, USA. (2011).

32. Aral, S., Brynjolfsson, E. \& Van Alstyne, M. Productivity effects of information diffusion in networks (2007).

33. Harrison, D. A., Mohammed, S., McGrath, J. E., Florey, A. T. \& Vanderstoep, S. W. Time matters in team performance: Effects of member familiarity, entrainment, and task discontinuity on speed and quality. Personnel Psychology 56, 633-669 (2003).

34. Ancona, D. G. Outward bound: strategic for team survival in an organization. Academy of Management Journal 33, 334-365 (1990).

35. Levitt, B. \& March, J. G. Organizational learning. Annual Review of Sociology 319-340 (1988)

36. Wuchty, S. What is a social tie? PNAS 106, 15099-15100 (2009).

37. Kilduff, M. \& Tsai, W. Social networks and organizations (Sage, 2003).

38. Lincoln, J. R. \& Miller, J. Work and friendship ties in organizations: A comparative analysis of relation networks. Administrative Science Quarterly 181-199 (1979).

39. Waber, B. N. et al. Organizational engineering using sociometric badges. In International Conference on Network Science, New York, NY (2007).

40. Eagle, N., Pentland, A. S. \& Lazer, D. Inferring friendship network structure by using mobile phone data. PNAS 106, 15274-15278 (2009).

41. Rogers, E. M. Diffusion of innovations (Simon and Schuster, 2010).

42. Uzzi, B. \& Lancaster, R. Relational embeddedness and learning: The case of bank loan managers and their clients. Management science 49, 383-399 (2003).

43. Constant, D., Sproull, L. \& Kiesler, S. The kindness of strangers: The usefulness of electronic weak ties for technical advice. Organization science 7, 119-135 (1996).

44. Nelson, R. E. The strength of strong ties: Social networks and intergroup conflict in organizations. Academy of Management Journal 32, 377-401 (1989).

45. Cronbach, L. J. Coefficient alpha and the internal structure of tests. Psychometrika 16, 297-334 (1951)

46. Falchikov, N. Product comparisons and process benefits of collaborative peer group and self assessments. Assessment and Evaluation in Higher Education 11, 146-166 (1986).

47. Kozlowski, S. W. \& Bell, B. S. Work groups and teams in organizations. Handbook of psychology (2003). 
48. Stopczynski, A. et al. Measuring large-scale social networks with high resolution. PLOS ONE 9 (2014).

49. Rammstedt, B. \& John, O. P. Measuring personality in one minute or less: A 10item short version of the big five inventory in english and german. Journal of Research in Personality 41, 203-212 (2007).

50. Sapiezynski, P. Measuring patterns of human behavior through fixed-location sensors (2013). URL www2.imm.dtu.dk/pubdb/views/edoc_download.php/ 6556/pdf/imm6556.pdf. (Date of access: 27/03/2014).

\section{Acknowledgments}

We thank Piotr Sapiezynski for his help in data collection and insights regarding wifi data, Vedran Sekara for his help in data collection, and Luc Rocher for his help with the network visualizations. We also thank the students for participating in the experiment. Yves-Alexandre de Montjoye thanks the Belgian American Educational Foundation (B.A.E.F.) for its financial support. This research was partially sponsored by the Army Research Laboratory under Cooperative Agreement Number W911NF-09-2-0053. Views and conclusions in this document are those of the authors and should not be interpreted as representing the policies, either expressed or implied, of the Army Research Laboratory.

\section{Author contributions}

Y.-A. de M. designed the experiment, analyzed the data, and wrote the paper; A.S. and E.S. designed the experiment and analyzed the data; A.P. and S.L. designed the experiment and wrote the paper.

\section{Additional information}

Supplementary information accompanies this paper at http://www.nature.com/ scientificreports

Competing financial interests: The authors declare no competing financial interests.

How to cite this article: de Montjoye, Y.-A., Stopczynski, A., Shmueli, E., Pentland, A. \& Lehmann, S. The Strength of the Strongest Ties in Collaborative Problem Solving. Sci. Rep. 4, 5277; DOI:10.1038/srep05277 (2014)

(2) This work is licensed under a Creative Commons Attribution-NonCommercialNoDerivs 4.0 International License. The images or other third party material in this article are included in the article's Creative Commons license, unless indicated otherwise in the credit line; if the material is not included under the Creative Commons license, users will need to obtain permission from the license holder in order to reproduce the material. To view a copy of this license, visit http:// creativecommons.org/licenses/by-nc-nd/4.0/ 